\title{
A Missão das Nações Unidas para Estabilização do Haiti: um olhar a partir dos relatos de um ex-soldado e de um repórter brasileiro*
}

\author{
Amanda Sanches Daltro de Carvalho1
}

\section{Introdução}

Esta resenha tem por objetivo fazer uma revisão bibliográfica de duas obras disponíveis na literatura brasileira sobre a Missão das Nações Unidas para Estabilização do Haiti-MINUSTAH. As obras "A República Negra" e "Um soldado no Haiti”, que darão subsídios ao artigo, são uma complementação e retificação de toda a discussão realizada no decorrer dos outros artigos inseridos neste livro.

A primeira obra sobre a MINUSTAH publicada no Brasil tem por título $A$ república negra: histórias de um repórter sobre as tropas brasileiras no Haiti. $\mathrm{O}$ autor Luis Kawaguti, repórter brasileiro, do Diário de São Paulo, acompanhou por alguns dias o trabalho dos soldados da MINUSTAH, em quatro visitas ao país caribenho.

Pouco tempo depois, estava à disposição nas livrarias o livro: Um soldado brasileiro no Haiti (RUPPENTHAL, 2007). Trata-se de Tailon Ruppenthal, um ex-soldado brasileiro que compôs o $1^{\circ}$ contingente militar que desembarcou no Haiti a serviço da Força de Paz da Organização das Nações Unidas, em 2004 e permaneceu durante 6 meses compondo a tropa de paz, no país. Destarte, o depoimento do soldado e o do repórter são construídos a partir de perspectivas contrárias, uma vez que o primeiro está intimamente ligado à missão e o segundo tem mais liberdade para explorar os fatos.

De qualquer maneira, as duas obras em questão apresentam fatos e depoimentos importantíssimos que corroboram com toda a discussão realizada nesta coletânea. Ambos convergem sobre a falha da Minustah na operacionalização do

\footnotetext{
* Recebido em 09.10.2009
}

Aprovado em 12.02.2010

1 Doutoranda em Política Internacional e Resoluções de Conflitos, do Centro de Estudos Sociais-CES e do Departamento de Economia, da Universidade de Coimbra. E-mail:amanda.sanches2@gmail.com 
que está disposto na Resolução 1542, que implementa a missão, a sua deficiência e a concentração apenas no componente militar, quando o que o Haiti ainda apresenta é um cenário de instituições frágeis e deficientes.

\section{Os brasileiros na MINUSTAH}

A obra "Um soldado brasileiro no Haiti", diferente dos relatos do repórter Luis Kawaguti, apresenta com frequência o lado emocional da missão, as relações interpessoais e o seu próprio objetivo, e, não somente, a sua operacionalização. As impressões sobre o país, o calor, a falta de água e de luz, os costumes haitianos, a relação com os militares e a solidão foram constantemente registrados no decorrer da obra.

Relata o soldado, no início do livro, sobre a primeira sensação que teve ao desembarcar no país caribenho: o calor haitiano que por várias vezes lhe causou mal estar. Ao descer do avião, logo avistou fogueiras que se espalhavam pelo entorno do aeroporto. Pensou o autor que isso era algum tipo de culto vodu, uma das principais práticas religiosas do Haiti, ao lado do catolicismo, informação que obteve nas suas pesquisas sobre o país.

Li algo sobre aqueles bonequinhos que eram espetados por agulhas longas e o nome de alguns deuses, mas nada me parecia muito profundo e quase todas as informações deixavam transpirar um enorme preconceito, [...] A realidade é muito simples: ninguém sabe nada sobre o Haiti. (RUPPENTHAL, 2007, p.9-10).

Os soldados que foram aprovados para participar da missão receberam treinamento insuficiente. Segundo Tailon: "O Exército deu um treinamento superficial, voltado sobre tudo para alguns aspectos da própria missão. Um dos cabos que viajou ao meu lado, Ferraz, chegou a perguntar em que parte da África ficava o Haiti” (RUPPENTHAL, 2007, p. 10). Outro militar questionava Ruppenthal sobre a situação política do Haiti. Respondeu, então:

[...] eu me lembrava da orientação pisada e repisada durante o treinamento para a missão de paz, para sempre demonstrarmos completa imparcialidade quando o assunto 
era política. Hoje, porém, estou convencido de que a missão da ONU servia a interesses bastante definidos. (RUPPENTHAL, 2007, p.15).

Não obstante à falta de informação, muitos não sabiam exatamente qual o papel que desempenhariam no país mais pobre das Américas, contudo, a maioria dos militares que aceitou participar da missão de paz almejava, em longo prazo, a possibilidade de alcançar outros patamares na hierarquia do Exército e, a curto prazo, seriam acrescidos novecentos dólares no salário de cada um. Isso, sem citar aqueles que queriam apenas “andar de avião” (RUPPENTHAL, 2007, p. 14).

Durante os treinamentos no quartel, os soldados tinham que repetir: "É preciso ter sangue nos olhos", lema que por muito tempo esperou para ser posto em prática por alguns militares que se juntaram à Tropa de Paz. E, para muitos, participar de uma missão que já havia sido iniciada pelos norte-americanos era uma vitória. Conclui o autor que "uma arma, na mão de um cara desses, é um troféu e, ao mesmo tempo, um enorme risco, [...]." (RUPPENTHAL, 2007, p. 12). Aliás, o primeiro contato com os norte-americanos deu-se no próprio aeroporto.

Foi o primeiro contato que tive com a truculência militar norte-americana. [...] Saudavam-nos dizendo que merecíamos o inferno do Haiti e que iríamos nos dar bem com toda a certeza, já que o Brasil devia ser igualzinho àquele atoleiro. [...] Não passaria muito tempo para que eu ouvisse diversos relatos de violência, desaparecimento e todo tipo de arbitrariedades que o Exército norteamericano teria cometido durante as primeiras semanas de ocupação militar no Haiti, depois da queda de JeanBertrand Aristide. [...] Corria o boato de que tinham sido eles, na verdade, que derrubaram Aristide [...] (RUPPENTHAL, 2007, pp. 16-17).

A expectativa de Tailon era, como tropa de paz, "levar ajuda humanitária, garantir a segurança do governo e tentar reorganizar, no que fosse possível, as instituições haitianas". Essa expectativa foi abortada quando percebeu que tinha que "combater homens armados que [...], ameaçavam tomar o poder" (RUPPENTHAL, 2007, p. 17) e "[...] isso significa que entre os nossos inimigos estavam os partidários de Aristide” (RUPPENTHAL, 2007, p. 57). Aliás, a única tarefa que o soldado desempenhou no período em que esteve no Haiti foi procurar milicianos, 
e a "instrução era perseguir alguém que se mostrasse assustado" (RUPPENTHAL, 2007, p. 105) com a presença da MINUSTAH.

Se não bastasse o desvio de função da missão, por várias vezes os militares e os civpols - Polícia das Nações Unidas- tinham que fazer a guarda de casas de haitianos que poderiam estar expostos a perigos. Esses indivíduos faziam parte da elite haitiana e disponibilizavam recurso suficiente para prover a sua própria guarda. Acontece que a Minustah deveria garantir a não violação dos direitos humanos dos haitianos, mas, para alguns, era dispensada atenção diferenciada por conta da sua colocação na sociedade haitiana. Ao passo que constantemente os direitos humanos dos indivíduos que viviam nas favelas de Porto Príncipe, capital do Haiti, eram absurdamente violados.

Em princípio, a tropa brasileira era sempre muito bem recebida e festejada, pelo fato de estar associada à solução dos problemas haitianos e também por representarem o país do melhor futebol. Mas aos poucos, a relação de "amizade" ou de proximidade entre brasileiros e haitianos diminuiu. Sobretudo, porque a tropa brasileira sempre esteve acompanhada pela Polícia Nacional Haitiana em suas ações e vice-versa. A parceria delimitada na Resolução 1542 entre a polícia haitiana e a ONU, na prática, mostrou-se constantemente debilitada e frágil. Na teoria, os papéis que cada instituição deveria desempenhar, mostraram-se impraticáveis na prática.

Também atendíamos a chamados que denunciavam o esconderijo de milicianos. Nesses, como em muitas outras buscas, íamos acompanhados de membros da Policia Nacional do Haiti, a PNH, detestada por quase toda a população. Vai ver que é por isso também que aos poucos os haitianos começaram a nos detestar: vivíamos andando com os policias que, em outras situações, aprontavam todo o tipo de barbaridade. Conheço gente que chegou a testemunhar integrantes da $\mathrm{PNH}$ encapuzados, esperando para atingir alguém. E, quando faziam isso, atiravam na cabeça ou no peito para matar mesmo. [...] Um pouco depois soubemos [...] que a PNH tinha uma ligação muito forte com algumas milícias. [...] Assim que recebíamos uma denúncia, partíamos com os policiais [...], mas eles já tinham avisado os milicianos dos nossos planos. [...] Portanto, ambas as milícias e a $\mathrm{PNH}$, enquanto não combatiam 
entre si, estavam do mesmo lado e atacavam a população partidária de Aristide. [...] Mas cheguei a ver muito cara gritando de medo: bastava um miliciano se ferir e ficar para trás (o que não é muito comum), enquanto o bando desapareceria, que, assim que chegávamos, o cara começava a berrar de temor, implorando para não ser transportado até o hospital pela polícia haitiana. [...] O sujeito tem certeza de que vai ser assassinado pela polícia, já que é um inimigo, e com requintes de crueldade - coisa que talvez já tenha feito com um policial -, e por isso chora desesperadamente (RUPPENTHAL, 2007, pp. 73-75).

Se não bastasse a conivência da tropa de paz com as atrocidades praticadas pela polícia haitiana, havia por outro lado, a pressão exercida pela ONU quanto aos resultados apresentados pelos militares. Nesse sentido,

[...] uns três meses depois do início da missão, no entanto, correu o boato de que um dos principais oficiais brasileiro tinha sido chamado pela ONU para explicar por que estávamos economizando munição. Aí as coisas mudaram. [...] Recebemos então a ordem de revidar qualquer agressão, de nos afastar das pessoas e de deixar a simpatia de lado. E foi o que fizemos: a cada emboscada, devolvíamos o ataque atirando também [...]. [...] A população, então, começou a se voltar contra nós. Para eles, a nossa presença estava aumentando a violência [...] (RUPPENTHAL, 2007, p. 50 e p. 136).

Ou seja, a tropa militar não estava respondendo de maneira eficaz as recomendações da Resolução 1542 de desmobilizar as gangues e ex-militares, e, consequentemente, fez-se uma associação quanto ao número de balas que estava sendo usado nas operações. Todavia, no protocolo de engajamento, no qual estavam descritas as regras da missão, os soldados só poderiam usar as armas caso a ofensa viesse primeiro do opositor. E esta ofensa se restringia estritamente ao disparo de armas contra os soldados. Se isso não ocorresse, os militares não poderiam usar seus instrumentos de trabalho, tampouco iniciar uma ofensiva. Em muitos casos, era recomendado que a patrulha fosse realizada sem armas.

Não só os problemas estruturais apresentados pela missão dificultavam a atuação dos capacetes azuis, mas também as condições precárias do país caribenho. O cenário haitiano era constituído por um sistema precário de saneamento 
básico. O lixo se acumulava nas ruas, misturado com corpos que apodreciam, com os urubus que se alimentavam deles e com as crianças que jogavam bola no mesmo espaço, "o país é um necrotério a céu aberto" (RUPPENTHAL, 2007, p. 22).

Mas essa observação já não se apresenta hoje. De fato, quando as tropas brasileiras desembarcaram no Haiti, havia pilhas e mais pilhas de lixos nas ruas. Entretanto, aos poucos a Minustah fomentou a limpeza das ruas, mesmo porque o lixo atrapalhava o deslocamento dos soldados, com seus tanques e urutus, e servia de trincheira para as gangues e ex-militares. Quando estivemos no Haiti, em janeiro de 2007, esse cenário apresentado por Tailon não se registrava. As ruas estavam mais limpas, via-se até caminhões trabalhando na coleta do lixo, o que não se podia imaginar antes da missão. Consequentemente, não nos deparamos com corpos pelo chão, mas avistamos porcos festejando em redutos de lixos afastados da cidade.

Nesse ambiente, no qual estavam inseridos os capacetes azuis, fomentava o uso de álcool e de drogas. Somado a isso, muitos soldados não aguentavam a pressão e desenvolviam depressão.

A solução encontrada por eles foi o álcool. No Haiti o pessoal também bebia muito. Escondíamos bebida no alojamento (sobretudo cachaça e cerveja) para tomar à noite. Mas aí o problema não era de alguns soldados apenas: todo mundo queria beber para esquecer o que tinha visto durante o dia. Se tivéssemos cruzado com algum cadáver de criança, então, a bebida não seria suficiente nem para começar (RUPPENTHAL, 2007, p. 29).

Diante da pobreza do país, da falência das instituições, do alto índice de desemprego e de miseráveis, conclui o autor:

É óbvio que a violência das milícias que fomos combater é causada por um problema estrutural que nada tem a ver com qualquer coisa que um Exército possa fazer. Acho que a missão da $\mathrm{ONU}$, liderada pelo Brasil ou quem quer que seja, pode ficar dez ou vinte anos no Haiti que nada vai mudar de fato, se não houver um trabalho consciente de transformação social (RUPPENTHAL, 2007, p. 87).

Poucos meses depois de Tailon Ruppenthal retornar ao Brasil, outro brasileiro desembarcava no devastado e caótico país caribenho. Luís Kawaguti, na época 
repórter do jornal O Diário de São Paulo, visitou a ilha por quatro vezes, entre maio de 2005 e março de 2006. Diferente do soldado, Kawaguti teve a oportunidade de desenvolver um trabalho mais investigativo, até mesmo por não estar vinculado a nenhuma das partes em questão, quando buscou estabelecer as diferentes visões dos autores envolvidos na missão.

Em “A República Negra: histórias de um repórter sobre as tropas brasileiras no Haiti”, Kawaguti refere-se ao Haiti:

Mas, para além da questão política internacional, estavam em jogo as vidas de 8 milhões de pessoas que habitavam o país mais pobre das Américas. Dono do mais degradado ecossistema do mundo, com cerca de $96 \%$ da vegetação devastada, o Haiti detinha o $25^{\circ}$ pior Índice de Desenvolvimento Humano (IDH) entre 173 países avaliados pelas Nações Unidas. Mais de $80 \%$ da população vivia abaixo do nível de pobreza extrema, com uma expectativa de vida de apenas 53 anos" (KAWAGUTI, 2006, p. 33).

O papel da ONU, como colocado pelo repórter, era o de apoiar o governo que foi constituído provisoriamente "para impedir que milícias rebeldes, guerrilheiros, gangues e o governo entrassem em choque e promovessem um massacre" (KAWAGUTI, 2006, p. 11). Mas, que, no entanto, esse governo não era legitimado pelo povo haitiano. E acrescenta que:

O papel da ONU era apoiar o governo provisório e protegêlo contra as milícias que se dividiam em pelo menos dois tipos: ex-militares interessados na recriação do Exército Nacional e gangues que dominavam em favelas, cujas ações políticas e criminosas às vezes se confundiam (KAWAGUTI, 2006, p. 13).

A história do país caribenho está gravada pelos sucessivos golpes militares e por curtos períodos democráticos. Diante dessa instabilidade política, a missão da ONU atentou-se principalmente aos grupos militares locais, os quais representavam risco à implementação da Minustah. Não foi por acaso que esses grupos foram contemplados no programa de reinserção, desmobilização e desarmamento.

Organizavam-se em grupos reduzidos, às vezes, até em duplas, no interior dos comissariados (as delegacias 
haitianas) abandonados pela polícia. Ali instalados, os ex-militares passavam então a resolver pequenos crimes e a manter um pouco de ordem em esfera local. Eram, ao mesmo tempo, policiais e juízes, punindo bandidos e resolvendo rixas entre os moradores. Por conta disso, as populações não só os aprovavam como também garantiam o seu sustento. [...] - Os ex-militares entram no programa de desarmamento, desmobilização e reinserção da ONU. [...] O problema é que o governo não consegue reintegrar essas pessoas na sociedade (KAWAGUTI, 2006, p. 93).

Ao decorrer da missão, percebeu-se que o esforço da ONU não poderia restringir-se apenas aos grupos militares locais, os quais foram reconhecidos incoerentemente pelo próprio governo provisório do Haiti, já que o desgoverno enfrentado pelo país lhe era atribuído. Contudo, o foco deveria voltar-se principalmente às gangues ou a grupos paramilitares que, em face da ausência do Estado, exerciam a jurisdição nas áreas de influência e dominação.

À medida que a missão encontrava e definia os seus alvos, outro problema, talvez o mais grave que deveria ser tratado urgentemente pela Minustah, era a forma como a Polícia do Haiti desenvolvia o seu trabalho. Como Tailon bem observou sobre a Polícia Nacional do Haiti, o repórter também confirmou, por meio de entrevistas não só com os componentes da tropa de paz, mas com os haitianos e observadores internacionais, que "a polícia haitiana roubava, estuprava e matava os partidários de Aristide".Esse fato tornava conflitante o objetivo da missão, já que a Tropa de Paz deveria apoiar tanto a Polícia Nacional Haitiana, quanto a população que estava em confronto constante (KAWAGUTI, 2006, p. 12). Relata o repórter:

A colina da favela de Bel Air amanheceu inquieta com a presença nas ruas da Polícia Nacional do Haiti (PHN), no dia 25 de fevereiro de 2005. Blindados brancos com as iniciais das Nações Unidas subiam letamente as ladeiras asfaltadas da favela. Sobre seus corpos metálicos, soldados brasileiros abriam caminho em meio a uma multidão negra revoltada contra a polícia e o governo. Por volta das 9 horas, na rua St. Martin, uma das principais de Bel Air, [...] policiais invadiram uma casa e, em minutos, estavam de volta à rua arrastando um homem desarmado, capturado enquanto tomava o café da manhã. Um dos policias fez pontaria com o fuzil. O tiro perfurou a região entre os olhos do haitiano $[\ldots]$. E os militares [...] assistiram às mortes do alto de um 
carro de combate Urutu sem interferir [...]. Apesar de oficial, o governo provisório não contava com a legitimação dos votos dos cidadãos do Haiti. A contradição dos capacetes azuis se dava na medida em que a ONU assumira duas missões que, por vezes, revelavam-se conflitantes. Segundo estabelecido pelo Conselho de Segurança da ONU, os capacetes azuis dariam suporte às ações da polícia haitiana. Por outro lado, deveriam também proteger a população, se preciso abrindo fogo contra quem a colocasse em perigo. As resoluções do Conselho de Segurança, porém, não incluíam um protocolo sobre o que fazer caso a própria polícia ignorasse os direitos humanos do povo do Haiti." Por volta das 9 horas, na rua St. Martin, uma das principais de Bel Air, a Companhia de Intervenção e Manutenção da Ordem atirou contra moradores. [...] segundo Samba Boukman, um dos lideres mais influentes, em Bel Air, [...] disse que outros 13 partidários do ex-presidente foram assassinados de forma semelhante naquela manhã. Militares brasileiros, atônitos, assistiram às mortes do alto de um carro de combate Urutu sem interferir, de acordo com Boukman." (KAWAGUTI, 2006, pp. 11-14).

Em uma das várias manifestações que ocorrem no Haiti, em defesa ao ex-presidente deposto, depõe o repórter sobre a atuação em conjunto da PNH e da tropa de paz da ONU:

Quase não acreditou ao ver seis homens da Companhia de Intervenção e Manutenção da Ordem (Cimo) da PNH, perfilados e com os fuzis apontados para os manifestantes. Os capacetes azuis sentiram na pele o ônus de uma missão com objetivos tão contraditórios. Afinal, naquela circunstância, como proteger a população e, ao mesmo tempo, apoiar as ações da polícia? Os brasileiros, então, cumpriram à risca seu dever, perfilando-se como escudo humano entre os manifestantes e os homens da Cimo, na esperança de evitar o iminente massacre. 'Allez, allez.. move, move', gritavam, tentando dispersar a multidão, enquanto faziam sinais com as mãos para que a Cimo abaixasse as armas. A turba, porém, sentindo-se protegida pelas Nações Unidas, passou a provocar os policiais. Os homens da $\mathrm{PNH}$ não se intimidaram. Ao contrário, lançaram granadas de gás lacrimogêneo sobre os soldados da ONU e contra a população, que começou a se dispersar. Além dos sons das explosões das granadas e dos gritos da multidão, o oficial brasileiro ouviu também tiros de fuzil - era a Cimo, outra vez. O capacete azul viu voar o sangue da cabeça de um 
manifestante de meia-idade, magro, alto e desarmado. O disparo tinha sido dado de uma distancia tão curta que o cérebro do haitiano foi arremessado para fora da caixa craniana. 'Por que vocês deixaram? Por que não atiraram neles?', questionava a população." (KAWAGUTI, 2006, pp. 61-62).

O fluxo estabelecido entre a tropa de paz e a Polícia Nacional Haitiana, $\mathrm{PNH}$, pode ser alvo de críticas. A tropa de paz ao deter qualquer cidadão haitiano, pelo método mais antiquado, encaminhava-o para a $\mathrm{PNH}$ que checava em uma lista se este era procurado (KAWAGUTI, 2006, p. 58). Sabendo da relação entre a $\mathrm{PNH}$ e os haitianos, principalmente aqueles que poderiam estar ligados a Aristide, o procedimento estabelecido entre as duas instituições é passível de todas as críticas negativas. A forma como eram realizadas as operações foi descrita por Kawaguti:

Os capacetes azuis abordavam pessoas suspeitas no Haiti segundo critérios físicos e de vestimenta, que ajudavam a identificar tanto rebeldes como membros de gangues. [...] Depois de deter o suspeito, as tropas de paz consultavam a polícia a fim de saber se a pessoa estava na lista dos procurados. Se estivesse, era entregue à $\mathrm{PNH}$; em caso contrário, os capacetes azuis o liberavam (KAWAGUTI, 2006, p. 58).

De forma isolada, tinha a própria atuação ou o modo de abordagem do contingente militar da missão:

Naquela noite, o arrombamento da porta - na verdade, um portão de ferro - foi inevitável, bem como o lançamento de uma bomba de gás lacrimogêneo casa adentro. Apenas uma criança e três mulheres estavam ali. [...] Os snipers, ou caçadores brasileiros, entravam em ação tanto de dia quanto à noite em Bel Air, Cité Soleil ou qualquer outra favela ou região- [...]. Suas ordens básicas eram simples: uma vez posicionados, tinham permissão para atirar em qualquer haitiano que fosse visto empunhando uma arma, exceto policiais (KAWAGUTI, 2006, pp. 124-125).

À pobreza haitiana também foi atribuída especial atenção pelo repórter. $\mathrm{O}$ autor relata a ação das ajudas humanitárias praticadas pelos militares da ONU, conhecidos por capacetes azuis, como forma de se conquistar a confiança da 
população local. Esse grupo prestava, inclusive, atendimento dentário e médico à população carente, já que a maior parte dos hospitais, no Haiti, é privado. Somado a isso, o grupo dos Médicos sem Fronteiras garantia, de certa forma, assistência à população que vivia nas duas favelas mais pobres: Bel Air e Cité Soleil.

\section{Conclusão}

A história haitiana é marcada por sucessivos golpes de estados e intercalada por fortes governos ditatoriais e de democracia frágil. É neste contexto que a Resolução 1542, aprovada pelo Conselho de Segurança da ONU, para o período de seis meses, colocou em prática a Missão das Nações Unidas para a Estabilização do Haiti - MINUSTAH, tendo em vista, o desafio de se estabilizar a política econômica e social haitianas e a ameaça deste país à paz e à segurança internacionais. Até hoje, já foram aprovadas 8 resoluções que autorizavam a continuidade da MINUSTAH. A última resolução aprovada é a 1840, de outubro de 2008.

A Minustah tem por pressuposto promover a implementação de três eixos: assegurar os direitos humanos do povo haitiano; promover a segurança nacional principalmente por meio dos programas de desarmamento, desmobilização e reintegração - DDR, voltados aos grupos armados e; apoiar a reconciliação dos grupos políticos do país além de possibilitar a realização das eleições.

À medida que a missão inova ao introduzir o componente dos direitos humanos no corpo da Resolução 1542, ela também comete um antigo erro de querer moldar o país, ao qual se destina a missão, aos seus programas. Nos relatos socializados acima não restaram dúvidas quanto aos insucessos colecionados pela ONU. É improvável, por exemplo, que o programa DDR apresente resultados, se ao desarmar um indivíduo, não se pode depois inseri-lo novamente na sociedade com um emprego digno, principalmente, porque o Haiti apresenta um índice de apenas $20 \%$ de haitianos empregados, enquanto que os demais estão vivendo na miséria.

Do mesmo modo, antes de se chegar a reintegrar de maneira correta um indivíduo na sociedade haitiana, têm-se as violações recorrentes praticadas pela 
polícia haitiana e pela tropa de paz. Ou seja, a missão incorre em dois antes. O primeiro no que se refere ao modo como o DDR está sendo operacionalizado e, o segundo, quando não se respeitam os problemas estruturais enfrentados pelo país.

Como bem expôs o soldado em sua obra: "A República Negra," os soldados de capacete azul no dever de participar das ações juntamente com a Polícia Nacional Haitiana acabam violando os direitos humanos do povo haitiano, que são permanentemente infringidos pela PNH. Agora, o problema da ONU não é apenas assegurar os direitos humanos, mas não ser mais uma transgressora. Destarte, ao contrário do que foi proposto pelo Conselho de Segurança das Nações Unidas, quando enquadrou a missão de paz no capítulo VI da Carta, observou o repórter:

A principal tarefa do terceiro contingente, formado por voluntários cariocas, era acabar o trabalho iniciado por seus predecessores paulistas: a ocupação e a pacificação de Bel Air. Para fazer isso, assim como os militares de outros países a serviço no Caribe, os brasileiros haviam recebido autorização da ONU para endurecer a missão de paz. Ou seja, as Nações Unidas classificam as missões de caráter militar de acordo com capítulos da Carta das Nações Unidas, assinada em 1945, que determina as condutas que devem ser adotadas pelos capacetes azuis no combate à violência. Quando os primeiros brasileiros desembarcaram no Haiti em 2004, a Minustah era uma missão classificada no Capítulo VI da Carta. Na prática, isso significava que os militares só poderiam disparar suas armas após terem sido agredidos a tiros. Poderiam atirar também se rebeldes atacassem civis ou o pessoal da ONU. No entanto, o "protocolo de engajamento" foi mudando à medida que a crise no Haiti se tornava mais violenta. Segundo o tenente coronel Jorge Antônio Smicelato, o segundo contingente enfrentou um perigo de nível 6,5 - uma adaptação da escala original - e o terceiro grupo de brasileiros desembarcou num Haiti classificado pelas Nações Unidas como 7, o mesmo nível adotado na Missão de Paz na Bósnia. Assim, a permissão para matar era estendida para casos em que o militar apenas se sentisse ameaçado (KAWAGUTI, 2006, p. 139-141).

Em março de 2005, foi publicado um relatório pela Universidade de Harvard sobre o desempenho da MINUSTAH. Além de confirmar as considerações que estão sendo feitas, aponta o documento que não houve progresso em nenhuma 
área de ação proposta pela Missão (CAVALLARO, 2005). Nele é relatado o abuso denunciado contra a PNH como prisões arbitrárias e detenções que se transformam em desaparições, sendo que, na maioria dos casos, essas ações, por várias vezes, tiveram a cobertura da MINUSTAH.

Conversei com civis haitianos num canto da Praça. Contaram-me que a maior preocupação do haitiano comum não era a Força de Paz da ONU, mas a própria polícia do Haiti que, durante certo período, atuou como principal órgão de repressão usado pelo governo provisório contra partidários do ex-presidente Aristide (CAVALLARO, 2005, p. 78).

O mandato de DDR da MINUSTAH é elogiado pelo relatório. Em termos gerais, esse mandato é mais "robusto" (CAVALLARO, 2005, p. 14) quando comparado aos implementados em Serra Leoa, por exemplo. Todavia, a falta de vontade política é um obstáculo para as suas execuções (CAVALLARO, 2005, p. 13) e seu desempenho é fraco em relação às outras Manutenções de paz. No que tange aos Direitos Humanos do povo haitiano, a missão só terá sucesso se os capacetes azuis entenderem "a centralidade de suas responsabilidades no tocante aos direitos humanos" (CAVALLARO, 2005, p. 20), como também mencionou o assistente do então comandante general Heleno de que o fraco da MINUSTAH é os direitos humanos (CAVALLARO, 2005, p. 22).

O Haiti, em decorrência da sua história de golpes de estado, da negligência dos governantes e mais recentemente pela destituição de Aristide da presidência, é um país que não tem, hoje, estrutura organizacional para oferecer aos seus cidadãos o mínimo de infraestrutura básica: água encanada, saneamento básico, luz elétrica, hospitais públicos, emprego, sistema penitenciário organizado, garantias constitucionais que assegurem o direito do contraditório e da ampla defesa, segurança pública, entre outros.

Ainda assim, nenhuma Missão de Paz terá sucesso enquanto não fornecer um contraponto entre o militar e o civil. Os militares são necessários para manter a ordem, mas, também, é preciso ensinar ou proporcionar os instrumentos à população para que haja a reprodução da manutenção dessa ordem, já que o Estado ainda não pode garanti-la. Não será o componente militar o responsável 
pela reestruturação de uma base política, do Estado Democrático de Direito e da implementação dos direitos humanos. A garantia de proteção aos direitos humanos num Estado considerado falido deve se dar de maneira diversa da que vem ocorrendo hoje no Haiti.

Além disso, a MINUSTAH não deixa ser uma missão que deu continuidade às outras já implementadas no país, após a saída do ditador Baby Doc. A Missão de Estabilização de Paz no Haiti nada mais é do que a tentativa de pacificar o caos que se instalou no país com a imposição, da Comunidade Internacional, de uma Democracia. Sem se aprofundar na discussão do que seria mais benéfico para o país, uma ditadura ou uma democracia imposta, não deixa de ser verdade que a saída repentina de Baby Doc da administração do país caribenho em nada mudou a situação haitiana porque os mesmos problemas apresentados anteriormente pelo país continuam ocorrendo.

A imposição da Democracia no Haiti não respeitou a sua debilidade institucional. E aí, esses recorrentes erros e violações continuarão sendo o retrato da missão, porque o status quo do país não mudou e da maneira como se interpreta e se operacionaliza a Resolução 1542, é fato que o Haiti não se desvencilhará dessas inúmeras intervenções que marcam a história do país.

\section{Referências}

CAVAllaro, James. Mantendo a paz no Haiti? uma avaliação da missão de estabilização das Nações Unidas no Haiti usando o cumprimento de seu mandato como parâmetro de sucesso. Cambridge, MA: Harvard Law Student Advocates for Human Rights; Rio de Janeiro, São Paulo: Centro de Justiça Global, mar. 2005.

KAWAGUTI, Luis. A república negra: histórias de um repórter sobre as tropas brasileiras no Haiti. São Paulo: Globo, 2006.

RUPPENTHAL, Tailon. Um soldado brasileiro no Haiti. São Paulo: Globo, 2007. 